\title{
La Condición Humana en el Martin Fierro
}

La literatura gauchesca argentina procede en parte de la literatura regionalista española y hereda sus alcances y limitaciones. No se trata sólo de reflejar en un lenguaje característico tipos, costumbres, modos de pensar y. de sentir propios de la región. Se transmite también, en forma más o menos consciente, una escala de valores a veces contraria a la tradicionalmente aceptada. El hombre de la región representa el ideal romántico de la vida natural; no está contaminado por los vicios de la civilización moderna. El paisaje casi virginal, sin las transformaciones que trae el progreso, simboliza ese estado. Pero se encubre también una protesta política y social. Todo regionalismo se opone a la centralización administrativa de los gobiernos liberales y lucha contra el desamparo social en que se tiene a los habitantes de la periferia. Los tipos humanos que el teatro o las escenas costumbristas solian presentar como ridículos o poco valiosos son ahora parte de una conciencia nacional alzada en defensa de las regiones postergadas. La amenaza de un movimiento de reivindicación pasa tanto por la literatura regional como por otras manifestaciones contemporáneas: los folletines sociales, por ejemplo. Aceptar pues la lengua característica de una región significa, para el público urbano, una actitud subversiva. Tenemos ejemplos similares en nuestro mundo actual: las actitudes de protesta comienzan casi siempre con un lenguaje propio que justificadamente molesta a la clase dominante.

Hispanoamérica coincide más con la periferia española porque está, frente a la lengua culta de la península, en parecida situación expresiva. El habla distintiva le sirve para firmar un diferente modo de vida. El regionalista, español o hispanoamericano, tiene conciencia no sólo de la lengua que crea sino también de la que excluye. Trata, de manera similar, de sorprender a los hombres cultos con el idioma propio de clases desvalidas y con la pintura de realidades desprovistas de la dignidad estética acostumbrada. 
También recibe Hispanoamérica las limitaciones de ese tipo de literatura. El regionalista debe, necesariamente, reducir sus pretensiones, conformarse con la descripción particular de un sector humano, más valiosa cuanto más ceñida a la lengua autóctona, a las caractetísticas de un paisaje diferente, de una tipología, a la percepción de un mundo distintivo. La literatura regional es literatura circular, de cierre. Todo lo que ocurre dentro de su círculo se ve como miniatura desde fuera; sólo quien se sitúa en su centro y logra salvar las barreras del lenguaje, percibe sus realidades con dimensión heroica. En una palabra, en la medida en que se escoge la expresión de lo regional se limita la posibilidad de transmitir una visión más amplia, una idea universal del hombre y de la vida. El tipo no suele aceptarse como símbolo genérico de la humanidad.

Algunos regionalistas como Trueba y Pereda en España, o como Hidalgo y Ascasubi en la Argentina, aceptan sus limitaciones y se conforman con la descripción pintoresca de tipos, costumbres y escenas; otros, como Rosalía de Castro o Hernández, con mayor talento expresivo y mejor manejo de su instrumento lingüístico, logran, sin traicionar la tradición que heredan, trasponer esas limitaciones y manifestar así una visión, personal y universal al mismo tiempo, del hombre y de la vida. Consiguen así convertir lo típico en genérico, lo individual en humano.

Hernández tiene cierta conciencia de que ha superado los modelos de la poesía gauchesca anterior. Nos dice que el Martín Fierro vale por algo más que la pintura de circunstancias locales y de hechos particularizados:

Más que yo y cuantos me oigan,

Más que las cosas que tratan,

Más que lo que ellos relatan

Mis cantos han de durar:

Mucho ha habido que mascar

Para echar esta bravata. ${ }^{1}$

Hernández es un poeta todavía romántico. Busca en la realidad símbolos de la trascendencia. El Martín Fierno, como el Don Juan de Zorrilla, tiene así una dimensión más alta que el simple relato de una aventura humana. Así como Don Juan simboliza una actitud eterna del hombre en la vida, Martín Fierro ejemplifica un modo de aceptar el destino que lo conviette en héroe arquetípico. Hay un modo de ser y un modo

1 Cito los números de versos y de páginas de la edición de Eleuterio Tiscornia, Martin Fierro. Comentado y anotado. Buenos Aires, Coni, 1925. Vs. 97-102, pág. 139. 
de vivir a lo Martín Fierro como hay un modo de ser y de vivit a lo Don Juan.

Si esa observación es cierta, corresponde preguntarnos qué aspectos de universalidad, susceptibles de ser entendidos por todos los hombres, por estudiantes educados en otras lenguas y otras culturas, por seres en fin que viven fuera del círculo en su región particular, de su lengua, de su circunstancia, logra el Marrín Fierro de Hernández transmitir.

Para acercarnos a la respuesta, debemos leer el poema en un nivel diferente del acostumbrado. El Martin Fierro, como toda obra de valor literario, of rece diversos niveles de lectura. El primero es el de la lengua: se trata de un poema campesino que refleja con conciencia de novedad $\rightarrow$ ello implica un nartador urbano y culto- la experiencia del habla rural y de la vida de campaña. El lector u oyente del poema, en 1872, si ciudadano y culto, captaría con sorpresa el sabor rústico de ese lenguaje; si hombre de campo, sólo percibiría este nivel como índice de realismo y de autenticidad. La crítica filológica sobre el Martin Fierro ha aclarado suficientemente las características de su lengua.

De inmediato percibimos un segundo nivel: el de la paremiología y el folklore. Hernández ha logrado una obra maestra de proyección folklórica. Su refranero aúna la tradición de la literatura gnómica española, también exaltada con el romanticismo por su carácter popular, con proverbios propios de la región rioplatense y, sobre este esquema, con otros que el autor crea llevado por la tendencia natural de la sextina al cierre sentencioso. La referencia del proverbio suele apelar a un conocimiento previo del lector, como cuando se compara, sin más explicaciones, con aquel cuervo que no volvió del mandao. ${ }^{2}$ El lector de campaña reconocería como propios muchos proverbios por la experiencia campera que reflejan o por su fondo de común experiencia humana. El folklore está presente, además, en la reelaboración de coplas populares y en la mención, no aclarada, de tradiciones como la de la luz mala u otras milagrosas como las de Santa Lucía o San Ramón. Este aspecto ha sido también estudiado: se han visto antecedentes del refranero de Hernández en obras literarias españolas (San Isidro Lubrador de Lope de Vega, el Diablo Mundo de Espronceda) o en recopilaciones de refranes populares. Augusto Cortázar explica el proceso de folklorización del poema de Hernández como cierre de un ciclo que comienza con el uso en él del folklore previo del Río de la Plata. ${ }^{3}$

Nada más atractivo para la masa de lectores que el relato de vidas

2 Vs. 731-732, pág. 165.

3 Augusto R. Cortázar, Poesía gaucbesca argentina. Buenos Arres, Editorial Guadalupe, 1969, pág. 80 . 
desventuradas de gauchos, verdaderas historias folletinescas. Hernández tiene en cuenta la necesidad de mantener vivo el interés de ese relato. Queremos saber cómo se salva Fierro de la partida, cómo se las arregla para vivir entre los indios, cuál es el fin de su aventura con la cautiva, cuál el destino de cada uno de sus hijos. Si en el uso del refranero, Hernández apela al reconocimiento de la experiencia reflejada en cada proverbio, en sus cuentos de gauchos, de indios y de negros, pide la compasión sentimental. Se acumulan los episodios patéticos: hijos desprendidos del seno de la madre como pichones sin emplumar, hogares destruidos por la agresión del individuo o de la justicia, persecución de inocentes, privaciones, desnudez, soledad afectiva, miseria y dolor. En el episodio de la cautiva se extreman los recursos efectistas destinados a despertar compasión, sobre todo en un público femenino. El autor sabe que está creando un cuadro de dolor; pues, con extraña transposición pone distancia entre el personaje y la escena para que éste contemple desde lejos, como un pintor, el suceso narrado y atestigüe:

\section{Tres figuras imponentes \\ Formábamos aquel terno: \\ Ella en su dolor materno; \\ $Y_{0}$ con la lengua dejuera, \\ $Y$ el salvaje, como fiera \\ Disparada del infierno. ${ }^{4}$}

Son historias que derivan de novelas de pícaros y de folletines sociales, en que también se cuentan desventuras de desamparados. El episơdio de la cárcel, y aun su intención crítica, recuerda escenas parecidas de folletines del siglo XIx o de obras de mayor prestigio literario, pero que recogen el eco de esos folletines, como el Diablo Mund'o de Espronceda. Por el carácter novelesco de estas historias, Borges quiere leer el Martín Fierro como novela en verso. ${ }^{5}$

El siguiente nivel de lectura se relaciona con las realidades que el poema refleja: costumbres gauchescas, vida de indios, situación de los fortines y de la campaña, trabajos agrícola-ganaderos, referencias políticas, pintura de la sociedad. Todo esto ha producido bastante literatura crítica. No la mejor, pero sí útil para aclararnos pasajes de significación algo oscura.

Queda todavía cierto nivel simbólico. El Martín Fierro ha sido leído

4 Vs. 1327-1332, pág. 187.

5 Jorge Luis Borges y Adolfo Bioy Casares, "Prólogo" a Poesía gaucbesca. México-Buenos Aires, Fondo de Cultura Económica, 1955, págs. XXI-XXII. 
también como un mito nacional, como la expresión auténtica del espíritu argentino. El valor, la rebelión ante la injusticia, cierta conducta del héroe entre solapada y atrevida, su actitud con respecto al amigo y a la mujer, se han considerado, sin que sepamos bien por qué, caracteres básicos del hombre argentino. En el mismo nivel, se ha visto el poema como símbolo de rebeldía social hasta el punto de considerárselo un manifiesto revolucionario de la clase obrera. ${ }^{6}$ Martínez Estrada y otros que han seguido sus pasos han estudiado este aspecto hasta la exageración.

Aún queda algo sin leer en el poema de Hernández una vez traspuestos esos niveles de lectura. Si eliminamos la palabra gaucho y los modos idiomáticos gauchescos, muchas de las estrofas del poema parecen estar hablando de otra cosa. EI Mkrtin Fierro quiere tener también una interpretación más amplia. Al menos en parte, la situación del gaucho perseguido sirve a Hernández como correlato objetivo para decirnos su idea sobre la situación del hombre en el cosmos, frente a Dios y a su destino. El Martin Fierro poetiza la condición humana como tema explícitamente desarrollado y como referencia constante de sus símbolos dramáticos. El uso del refranero en su estructura se justifica precisamente en cuanto ayuda a sentir como genérica la experiencia particular, con lo que se convierte en propio del hombre lo que de otro modo sería propio del gaucho. Salvo algunas referencias de Lugones y de Rojas, nadie ha dicho demasiado sobre este nivel propuesto. Martínez Estrada merece consideración especial: habla del simbolismo universal del poema en la última parte de su Muerte y transfiguración del Martin Fierro, en el corto capítulo que denomina Las esencias.

Martínez Estrada ve el poema como un símbolo de tenores abstractos, a los personajes como vehículos cuya significación se agota una vez entregado el mensaje que transmiten. Se trata de un mensaje social, y únicamente social. Martín Fierro es así el arquetipo de una clase social; su vida es la vida de todos los gauchos: "Los hechos de que participa Martín Fierro son 'pruebas' de sus desdichas y él a la vez una 'prueba' de la desdicha instaurada como una télesis del proceso social, que se reproduce a escala reducida en cada uno de los agonistas."7 Limita pues el nivel simbólico del poema a esa interpretación sociológica.

Además, Martínez Estrada exagera el fondo pesimista del poema. El argumento, dice, evidencia que "está en las cosas y en las personas el mal, $\mathrm{y}$ aún las víctimas están infeccionadas de tal manera que cooperan

${ }^{8}$ Eduardo B. Astesano, Martín Fierro y la justicia social. Primer manifiesto revolucionario del movimiento obrero argentino. Buenos Aires: Ediciones Relevo, 1963.

7. Ezequiel Martínez Estrada, Muerte y transfiguración del Martín Fìrro. México-Buenos Aires, Fondo de Cultura Económica, 1942; volumen 2, pág. 489. 
con la acción destructota de los entes abstractos." ${ }^{\text {nn }}$ mecanismo poderoso se mueve detrás de las vidas humanas impidiendo cualquier tentativa de libertad. Lo que corresponde es pues el renunciamiento, el abandono de toda esperanza, la renuncia de los bienes perdidos: "No hay más que dos salidas: comprender y resignarse, como el viejo Vizcacha, que hace su juego, adaptado hasta la insensibilidad a su mundo, o confesar la informe fuerza del destino, cuyo rostro de lóbrega divinidad percibimos en el poema con mayor nitidez que los mismos personajes."'

No sé si se refiere a un pesimismo relativo con respecto a esa télesis social o a un pesimismo más amplio que implique una concepción determinada de la vida. No advierto pesimismo social. Por lo menos, en el punto de vista del autor, que escribe un poema reivindicatorio y cree, por lo tanto, en posibilidades de mejoramiento. Hernández asegura a sus lectores:

$Y$ han de concluir algún día

Estos enriedos malditos. ${ }^{10}$

Mas Dios ha de permitir

Que esto llegue a mejorar,

Pero se ha de recordar

Para hacer bien el trabajo

Que el fuego, pa calentar

Debe ir siempre por abajo. ${ }^{11}$

Propone incluso un programa de mejoras: el gaucho, dice, debe tener casa, iglesia $y$ derechos. ${ }^{12}$ Se presenta él mismo como defensor de esa clase contraponiendo su actitud moral a la de los políticos gobernantes:

$\mathrm{Y}$ en lo que esplica mi lengua

Todos deben tener fe;

Ansí, pues, entiendanmé.

Con codicias no me mancho:

No se ha de llover el rancho

En donde este libro esté.13

8 Ibid., págs. 489-490.

9 Ibid., pág. 491.

10 Vs. 4829-4830, pág. 361.

11 Vs. 4835-4840, pág. 362.

12 Vs. 4827-4828, pág. 361.

13 Vs. 4853-4858, pág. 363. 
Hay mucho en el poema de panfleto político orientado precisamente a convencer de que las cosas deben cambiar en la provincia de Buenos Aires, de que debe haber una política agraria e, incluso, de que Hernández, hombre sin codicia, puede producir esas reformas.

No debe, pues, tratarse de este tipo de pesimismo. Con respecto a la concepción más amplia, debe reconocerse que el del Martín Fierro no difiere del pesimismo cristiano de la novela picaresca, exaltadora de otros bienes ultraterrenos, o del propio de la literatura barroca del desengaño, en especial de Quevedo y Calderón. Nietzsche y Schopenhauer están muy lejos todavía.

El Martin Fierro reitera una visión cristiana del mundo, en la que cualquier pesimismo con respecto a la vida en la tierra sirve sólo de trampolín para la afirmación de valores religiosos. Hay un deliberado propósito en Hernández de convertir a Martín Fierro en un héroe cristiano. Dios está constantemente en el pensamiento y en la palabra del gaucho. En casi un centenar de estrofas se menciona a Dios y a su relación con el hombre. Se lo llama Dios, Eterno, Criador, Señor, Eterno Padre, Divina Majestá, Ser de todos los seres. Se lo invoca constantemente: Dios te asista, que Dios quiera, Bendito Dios. También se invoca a Cristo, a Ja Virgen María, a Todos los Santos, a santos particulares como San Martín. Se pone a Dios como testigo de los actos humanos: cuando se empieza a cantar, se entra en pelea, se busca refugio entre los indios. El gaucho reza en cuanta ocasión lo prescribe la iglesia o la costumbre. Cumple con otros ritos de la religión católica. Cuando mata, junta osamentas, reza un bendito, hace una cruz y pide perdón por sus pecados. Cuando muere Cruz lamenta no saber una oración para ayudarlo a bien morir, lo entierra con sus propias manos y ruega por su alma. Al llegat a las poblaciones besa la tierra "En humilde vasallaje - a la majestá inifinita." 14

Martín Fierro y sus hijos se diferencian de Picardía por su fe religiosa. En los momentos de mayor desesperación, el héroe confía en el amparo divino. En el desierto, donde no se puede esperar auxilio humano, "sólo de Dios hay amparo."15 Y ampara es palabra significativa en este poema de los desamparados sociales. Cuando el indio, en el episodio de la cautiva, resbala accidentalmente sobre el cadáver del niño recientemente asesinado, Fierro ve en esa casualidad un acto de la Providencia:

Para esplicar el misterio

Es muy escasa mi cencia:

14 Vs. 1535-1536, pág. 196.

15 Vs. 1487-1488, pág. 194, 
Lo castigó, en mi concencia, Su Divina Majestá:

Donde no hay casualidá

Suele estar la Providencia. ${ }^{16}$

Sobre todo, se exalta a Dios como creador del mundo y del hombre. El Dios creador corresponde mejor en un poema en que se plantea descarnadamente la lucha del hombre por sobrevivir en su ámbito natural. Dios es creador generoso que ha volcado sobre los seres la prodigalidad de sus dones. Toda la naturaleza lo evidencia: las flores poseen color, los pájaros canto y vuelo, fuerza o astucia las fieras.

El tema de los bienes concedidos al hombre aparece ampliamente desarrollado, y en estrofas que se destacan por la altura del pensamiento y la ausencia de pintoresquismo expresivo. Podrían pasar sin desdoro a la literatura de estirpe calderoniana:

Dios formó lindas las flores,

Delicadas como son;

Les dió toda perfeción

Y cuanto él era capaz;

Pero al hombre Je dió más

Cuando le dió el corazón.

Le dió claridá a la luz, Juerza en su carrera al viento, Le dió vida y movimiento

Dende la águila al gusano;

Pero más le dió al cristiano

Al darle el entendimiento.

$\mathrm{Y}$ aunque a las aves les dió

Con otras cosas que inoro,

Esos piquitos como oro

$Y$ un plumaje como tabla,

Le dió al hombre más tesoro

Al darle una lengua que habla.

$Y$ dende que dió a las fieras

Esa juria tan inmensa,

16 Vs, 1303-1308, pág. 186. 
Que no hay poder que las vensa

$\mathrm{Ni}$ nada que las asombre

¿Qué menos le daría al hombre

Que el valor pa su defensa? ${ }^{17}$

Esos dones otorgados al hombre difieren en algo de los atribuidos en la literatura de procedencia teológica. El valor no figura entre los mencionados por Caldetón en sus Autos sacramentales. Hernández 10 cree don necesario en ese ambiente del desierto y equivale allí, en el hombre, a la fiereza y fuerza de las bestias. Es un don general de todos los hombres, no privativo del héroe, aunque en él se dé en grado más alto. Hernández ha querido que su héroe fuese paradigma de la especie humana; ser en quien todos los dones alcanzan extraordinaria dimensión: mejor entendimiento, más sentimiento, palabra extremada en el canto, valor indomable.

El valor es una virtud práctica, que permite sobrevivir. Forma, con la astucia y la prudencia, una tríada necesaria. La astucio aparece también en los animales. Suele convertirse, sobre todo en la edad juvenil, en picardia, en modo de eludir la responsabilidad y el riesgo. En el hombre maduro se transforma en prudencia:

Que el hombre muestre en la vida

La astucia que Dios le dió. ${ }^{18}$

Nace el hombre con la astucia

Que ha de servirle de guía;

Sin ella sucumbiría,

Pero, sigún mi esperencia,

Se vuelve en unos prudencia

$Y_{\text {en }}$ los otros picardía. ${ }^{19}$

En Martín Fierro se ha convertido en prudencia. En la primera parte, es un héroe aún incompleto: es imprudente. A imprudencia achaca la muerte del Moreno, vivida como una culpa, cuando quiere enmendarse. En la segunda parte, se valora a Cruz como varón humano y prudente. Desde entonces, Martín Fierro crece a medida que la obra se adelanta: pasa de la imprudente juventud a la prudente madurez. La prudencia es una de las virtudes que procura transmitir a sus hijos:

17 Vs. 2155-2178, págs. 120-121.

18 Vs. 173-174, pág. 18.

19 Vs. 4673-4678, pág. 348 . 
Se debe ser más prudente

Cuando el peligro es mayor;

Siempre se salva mejor

Andando con alvertencia,

Porque no está la prudencia

Reñida con el valor. ${ }^{20}$

El hombre ha de ser prudente

Para librarse de enojos;

Cauteloso entre los flojos,

Moderado entre valientes. ${ }^{21}$

También ha conferido Dios dones para la vida de relación como el sentido del amor, otorgado a todas las creaturas, y el de la amistad, privativo del hombre. El Moreno entona un canto al amor universal:

Ama el pájaro en los aires

Que cruza por dondequiera,

$Y$ si al fin de su carreta

Se asienta en alguna rama,

Con su alegre canto llama

A su amante compañera.

La fiera ama en su guarida

De la que es rey y señor.

Allí lanza con furor

Esos bramidos que espantan,

Porque las fieras no cantan:

Las fieras braman de amor.

Ama en el fondo del mar

El pez de lindo color.

Ama el hombre con ardor,

Ama todo cuanto vive.

De Dios vida se recibe

$\mathrm{Y}$ donde hay vida hay amor. ${ }^{22}$

Claro que se trata de un intermezzo lírico o retórico. Los hechos particulares como el adulterio de la mujer de Cruz o la infidelidad obligada

20 Vs. 241-246, págs. 147-148.

21 Vs. 4645-4648, págs. 344-345.

22 Vs. 4193-4210, pág. 322. 
de la mujer de Fierro empañan ese canto de amor. Pero tanto como esos hechos vale la presencia siempre añorada de la mujer y su asociación con todo bien perdido, con toda esperanza futura. No importa tanto la actitud del viejo Vizcacha, contra lo que supone Martínez Estrada; porque cualquiera sea la calidad literaria del retrato, Vizcacha encarna lo innoble. Importa la visión de Fierro, y quizá la del Moreno. Fierro valora altamente a la mujer cuando contempla el trato descomedido de los indios hacia sus chinas. Una mujer, María, redime al gaucho de sus delitos y le permite el gesto caballeresco y generoso.

Sin embargo, la mujer y el amor están ausentes; eran más propios de la vida durante la edad dorada del gaucho. La amistad es bien más imprescindible en la soledad del desierto. El hijo mayor, privado de toda comunicación en el presidio, destaca la importancia de la amistad:

Pues que de todos los bienes,

(En $\mathrm{mi}$ inorancia lo infiero)

Que le dió al hombre altanero

Su divina majestá,

La palabra es el primero,

El segundo es la amistá. ${ }^{23}$

Cruz se justifica en el poema en cuanto simboliza dramáticamente la presencia en el héroe de ese sentimiento humano. Es la amistad lo que modifica a Fierro y lo devuelve a la vida de la civilización.

Privado de sus bienes, el hombre se convierte en un animal. Así lo dice el hijo mayor:
$Y$ uno en condiciones tales
Se convierte en animal,
Privao del don principal
Que Dios hizo a los mortales. ${ }^{24}$

En el desierto, Fierro se queja, "Privado de tantos bienes". ${ }^{25}$ No hay mayor infierno que la cárcel. En el infierno de Dante, el mal resulta de la privación.

El hombre hernandiano, como sus predecesores en la poesía romántica, vive en la tierra como un desterrado. Ha perdido la unidad fundamental, la perfección primera. La edad de oro del gaucho vale un poco como

\footnotetext{
23 Vs. 2019-2024, pág. 211.

24 Vs. 2009-2012, pág. 211.

25 Vs. 967, pág. 175.
} 
símbolo de la perfección paradisíaca. En la soledad de la cárcel, el hijo mayor adivina la idea de la perfección. ${ }^{26}$

En la payada con el Moreno se debaten precisamente las consecuencias de la pérdida de comunión con Dios. El hombre ha visto la unidad convertirse en diversidad, la eternidad en tiempo medido. Hetnández conoció sin duda modelos de literatura proverbial, algunos de los cuales indica Tiscornia, en que esas ideas apatecen. Sem Tob, por ejemplo, afirma que el hombre ha puesto nombre a las cosas, y entre ellas al tiempo, por haber perdido su relación unitaria con la divinidad. Estamos encerrados bajo el cielo, dice, hemos hecho el día y la noche como modos de medir el tiempo, y. no sabemos nada más. Hemos llamado mundo al mundo y no sabemos qué es verdad ni qué es mentira. No es un sabio el que nos ha ayudado a poner al mundo un nombre certero, sino nosotros en nuestro afán de medir. El tiempo es relativo: el mismo camino dura un día para unos, dos días para otros. Dios es siempre uno, pero todos los nacidos se han alejado de esa unidad, están divididos. ${ }^{27}$ Martín Fierro responde al Moreno con ideas parecidas:

Uno es el sol, uno el mundo, Sola y única la luna;

${ }^{26}$ Metido en esa prisión,

De tanto no mirar nada,

Le nace y queda grabada

La idea de la perfeción. Vs. 1901-1904, pág. 207.

27 So un cielo toda vía

Encerrados yazemos.

Faze mos noche e día

$\mathrm{E}$ nos al non sabemos.

A esta lueñe tierra

Mundo posymos nombre.

Si verdat es o mentira

Del mas non sabe omne.

E ningún sabidor

Nol puso nombre cierto

Sy non que contador

Es de su mecimiento.

Peones que camino

Uno anda en quanto

Tienpo, el otro vino

Grant jornada dos tanto.

El siempre uno es

Mas todos los nacidos,

Como faz e enues

Asy son departidos.

Libro del Rabi Don Santob. Cambridge, 1947, pág. 146. 
Ansí, han de saber que Dios

No crió cantidá ninguna.

El Ser de todos los seres

Sólo formó la unidá;

Lo demás lo ha criado el hombre

Después que aprendió a contar.

Moreno, voy a decir

Sigún mi saber alcanza.

El tiempo sólo es tardanza

De lo que está por venir;

No tuvo nunca principio

Ni jamás acabará,

Porque el tiempo es una rueda,

$Y$ rueda es eternidá.

$Y$ si el hombre lo divide

Sólo lo hace, en mi sentir,

Por saber lo que ha vivido

$\mathrm{O}$ le resta que vivir..28

No quiero decir que Sem Tob haya influido en Hernández. Hernández ni debió conocer su existencia. Pero sí que en la payada se tienen en cuenta disputas de origen teológico en que se habla del hombre desterrado del Paraíso terrenal. Ocurre que en Sem Tob, mejor que en otros autores citados por Tiscornia, se dan juntamente el carácter de disputa teológica y la forma sentenciosa.

El hombre, alejado de la unidad primera, sufre en la tierra los infinitos males que Dios distribuyó junto con los bienes. El mayor de los males está vinculado con la idea de la muerte. El hombre quiere vivir libre, como el pájaro en el cielo, pero su libertad es ilusoria. Un destino inconstante, o suerte rigorosa, que rueda como bola, impone su dura ley. No tiene el hombre albedrío. En Hernández, como ocurre con la filosofía estoica, la única libertad consiste en combatir el destino o aceptarlo. Y el gaucho sabe que es inútil luchar contra esa fuerza. Martín Fierro es arrastrado por un destino extraño, como el personaje del Duque de Rivas, Don Alvaro, o como el Don Juan, hermanos del gaucho en este sentido:

No hay fuerza contra el destino

Que le ha señalao el cielo. ${ }^{29}$

28 Vs. 4307-4314, pág. 328; vs, 4349-4360, pág. 330.

29. Vs. 2011-2012, pág. 112. 
Yo ruedo sobre la tierra

Arrastrao por mi destino, $\mathrm{Y}$ si erramos el camino...

No es el primero que lo erra. ${ }^{30}$

Si hemos de salvar o no,

De esto naides nos responde;

Derecho ande el sol se esconde

Tierra adentro hay que tirar.

Algún día hemos de llegar,

Después sabremos adónde. ${ }^{31}$

Al destino se lo conoce sólo por las consecuencias de sus designios. Es una ley inexorable y cruenta que no puede evitarse y ante la cual sólo cabe la resignación:

No le merman el rigor

Los mesmos que lo socorren;

Tal vez porque no se borren

Los decretos del destino,

De todas partes lo corten

Como ternero dañino. ${ }^{32}$

Pero firme en mi camino

Hasta el fin he de seguir:

Todos tienen que cumplir

Con la ley de su destino. ${ }^{33}$

Lo que la suerte destina

No puede el hombre evitar:

Porque el cardo ha de pinchar

Es que nace con espina. ${ }^{34}$

Cuando al final de su peregrinaje, Martín Fierro encuentra a sus hijos y piensa reintegrarse a la vida social, la casualidad o la suette lo reúne con el negro poeta, hermano del que él mató en pelea. No sentimos forzado el argumento; aceptamos como verosímil ese encuentro, quizá

эo Vs. 2199-2202, pág. 122.

s1 Vs. 2203-2208, pág. 122.

si2 Vs. 1725-1730, pág. 201.

33 Vs. 4483-4486, pág. 335.

34 Vs. 357-360, págs. 151-152. 
no $\tan$ casual. Advertimos que el destino está otra vez barajando las cartas. El negro lo siente como misterio inexplicable:
$\mathrm{Y}$ es misterio tan projundo
Lo que está por suceder,
Que no me debo meter
A echarla aquí de adivino:
Lo que decida el destino
Después lo habrán de saber. ${ }^{35}$

Los cuatro gauchos lanzados a los cuatro vientos, parecen cuatro dados que la suerte echa sobre un tablero: cada uno jugará su papel perseguido más que por la justicia por ese destino cruel, esa "lóbrega divinidad" que. no parece saciarse.

Pero afortunadamente Hernández no se detiene en formulaciones abstractas sobre el hombre y el destino. Martín Fierro derrota al negro precisamente por tener los pies plantados en la tierra y despreciar las abstracciones de los poetas de fantasía. En cambio, Hernández sabe crear los símbolos dramáticos que transmiten más concretamente el mensaje que quiere sugerir. Al poner a un hombre o a un grupo de hombres solos frente al desierto crea ya el símbolo dramático de la vida humana. El hombre lucha, con los dones que Dios le ha dado, en un mundo lleno de agresiones y peligros. Frente al hombre, el paisaje. En el desierto, como en la vida, la busca del refugio es constante. El vientre de la madre es el primer refugio perdido: desde él se viene a cantar, que es lo mismo que a sufrit. El amor también se vive como refugio. El hombre perseguido busca guaridas o cuevas animales, cualquier lugar en qué ampararse. A veces, le basta la simple marcación de un espacio: dos cueros en forma de bendito, dormir con la cabeza señalando el rumbo, mirar las estrellas, recostarse sobre el caballo.

El hombre vive en el desierto en continua tensión. Un peligro le acecha: la muerte. Todos los seres viven de los otros, en constante rapiña. El hambre hace cruel a todo animal, más al hombre, que aunque ríe $y$ llora come a todo ser viviente, tenga pluma, escama o pelo. Las osamentas de animales y de hombres blanquean en el suelo. La muerte se siente en el poema como descarnada muerte natural, como último desamparo. Si no media el entierro, los caranchos hacen presa del cadáver.

El valor fundamental del poema de Hernández está en esa pintura cruel, naturalista, casi barojiana, de la lucha por la vida. En el desierto,

35 Vs. 4463-4468, pág. 335. 
el hombre puede animalizarse si pierde su dignidad. En todo el poema, los personajes se mueven como animales, confiados sólo en sus instintos, acechando los riesgos. Las comparaciones de actitudes humanas con gestos animales es un gran hallazgo expresivo de Hernández. Ve el mundo animalizado como modo poético de aludir a riesgos y agresiones. El hombre no se mueve: corcovea, rumbea como el cerdo, se agazapa, se esti$\mathrm{ra}$, mueve el cuello como cigüeña o avestruz, recula. Pelear es realizar una faena, carnear un animal. No se mata, se ensarta. El cuchillo corta, divide. Sus tajos dejan ver las tripas, el sebo. Toda la mecánica de los gestos particulares alude a un mundo animal: amar es prenderse como guacho de la teta; tomar mate, prenderse al cimarrón hasta ponerse rechoncho. Si uno no trabaja, cría sebo; si se rebela, hincha el lomo; si lo castigan en el cepo es para estirarlo como guasca fresca; cuando lo persiguen tiembla como yeguarizo o como palomas asediadas por los gavilanes. El gaucho ladra de pobre. Escapar del peligro es salvar el cuero. El indio, sobre todo, es un animal. Tiene nombre de animal, aprende $\mathrm{d} \epsilon$ los animales gestos y virtudes. En la lucha, echa espuma por la boca; para matarlo, se le pisan las paletas, se le hace estirar la geta. El viejo Vizcacha es también desde el apodo un animal despreciable: tiene patas de loro, actitudes de animal ladtón. Vive entre los perros; los perros le comen la mano al morir. Hasta las bromas hirientes que caracterizan el humor trágico de Fierro son comparaciones con animales, con vacas, con víboras, con lagattos. En ese mundo animalizado el gringo de la mona es tan exótico como la mona que trae.

Hernández nos acostumbra de tal modo a este esquema de símbolos, que le basta luego la simple mención para situatnos en una escala de dignidades. Si compara con águila, león, tigre, caballo o pájarto, exalta; si compara con ratón, cerdo, gato o vizcacha, disminuye. El pájaro es e] ser más alto: con él se compara al héroe cuando canta, cuando ama, cuando se siente libre. La metáfora más desarrollada en el poema es la del pájaro que vive feliz en su nido y lo pierde. Los pichones, sin emplumar todavía, andan desde entonces en busca de comida y de abrigo. El pájaro canta, en su dolor, en busca de consnelo. Hernández quiere lograr la compasión para sus criaturas: la imagen del pájaro sirve bien este propósito.

A medida que la animalización del mundo se completa y desarrolla coincide o contrasta con la dignidad del héroe. En los momentos cumbres de la animalización, la lucha con el indio y la vida del hijo con Vizcacha, los personajes están en la cima de su sentimiento humano y religioso.

Para Hernández, la vida es sufrimiento. No hay mayor dolor que la privación de los bienes, que la profunda soledad. Es en la cárcel donde 
asistimos al vértice de la soledad y de la angustia. Allí, como en el infierno dantesco, queda afuera la esperanza. ${ }^{36} \mathrm{La}$ estrofa más sentida del poema, aparece en la escena de la cárcel. El hombre está tan sólo que cuenta las pulsaciones de las lágrimas, el tiempo que tardan en secarse:

Cuenta esas horas eternas

Para más atormentarse:

Su lágrima al redamarse

Calcula en sus afliciones,

Contando sus pulsaciones

Lo que dilata en secarse. ${ }^{3 r}$

La calidad expresiva de esos versos vuelve a llevarnos a la inconsciente comparación con Dante. Se me ocurre que Hernández conocía bien a los poetas italianos: Dante, en especial; pero también Leopardi, presente en la imagen del pájaro arrancado del nido y de su canto doloroso.

El hombre debe aceptar el sufrimientc. Martín Fierro no se rebela contra el destino humano. No repite la actitud sublime de los héroes románticos; no impreca a Dios ni utiliza el humor satánico. Por el contrario, en plena desesperanza, el héroe promete respetar a Dios, aunque de Dios abajo, a ninguno. Existe un solo intento de rebeldía satánica:

Vamos suerte, vamos juntos,

Dende que juntos nacimos;

$Y$ ya que juntos vivimos

Sin podernos dividir,

Yo abrité con mi cuchillo

El camino pa seguir. ${ }^{88}$

La estrofa es una reminiscencia del Don Juan. Ante situación similar, en que el destino lo ha llevado a matar a un hombre, el Don Juan va, sin embargo, más lejos que Martín Fierro:

Allá voy.

Llamé al cielo y no me oyó, $Y$ pues sus puertas me cierra,

30 Vs. 1825-1826, pág. 204. Ver Martínez Estrada, volumen 2, pág. 490.

37 Vs. 1887-1892, pág. 207.

38 Vs. $1385-1390$, pág. 79. 
De mis pasos en la tierra

Responda el cielo y no yo. ${ }^{39}$

Hernández renuncia a toda actitud de rebeldía satánica. Aleja también la idea del suicidio:

De ese modo nos hallamos

Empeñaos en la partida:

No hay que darla por perdida

Por dura que sea la suerte,

Ni que pensar en la muerte

Sino en soportar la vida. ${ }^{40}$

En una palabra, el héroe es un resignado. Hernández pide a los lectores que pongan su esperanza en el Dios que lo formóti y aconseja resignarse:

Mas quien manda los pesares

Manda también el consuelo;

La luz que baja del cielo

Alumbra al más encumbrao,

Y hasta el pelo más delgao

Hace su sombra en el suelo. ${ }^{42}$

En última instancia, como recuerda el hijo mayor, Cristo sufrió males similares. La filosofía práctica del gaucho se expresa por boca de Cruz:

\section{Hagamoslé cara fiera}

A los males, compañero. ${ }^{43}$

Martínez Estrada se equivoca al conferir al héroe carácter de rebeldía y achacar al lector, en cambio, la actitud de resignación, la moral de los esclavos. ${ }^{44}$ El Martín Fierro es un poema que defiende el valor de la experiencia humana, aún la que deriva del sufrimiento. Nada enseña tanto como el sufrir y el llorar.45

\footnotetext{
39 Vs. 57-60, Don Juan Tenorio por José Zorrilla, en Nineteenth Century Plays al cuidado de Lewis E. Brett, New York, Appleton, 1935, págs. 343-344. 40 Vs. 331-336, págs. 150-151.

41 Vs. 2311-2312, pág. 128.

42 Vs. 367-372, pág. 152.

43 Vs. 1717-1718, pág. 94.

44 Op. cit., pág. 491.

45 Vs. 125-126, pág. 15.
} 
En resumen, Hernández dramatiza en sus historias otra historia fundamental y siempre repetida, que no es sólo el drama de una clase social. Es la historia del hombre, creado por Dios con excelsos dones como la inteligencia, el sentimiento, la palabra, el valor, el amor, la amistad, la astucia y la prudencia. El hombre, alejado de la perfección, lucha con esos dones como únicas armas para sobrevivir en un mundo cruel. Lo guía un destino prefijado, cuya finalidad ignora. Vive en medio de agresiones: debe buscarse comida, abrigo, defenderse, mätar para vivir, morir. Corre el riesgo de convertirse en un animal cruel y vengativo. Pero en la medida en que el mundo es más agresivo, el hombre heroico sabe mantener altos los dones de Dios; sabe exaltar su propia dignidad. E] héroe es no sólo el más fuerte en la lucha por la existencia, sino también es capaz de soportar el dolor y convertirlo en experiencia de vida. Así, el héroe da cima a la dignidad humana expresada en el amor, la amistad, la plegaria y el canto.

¿Cómo ha podido leerse el Martín Fierro como un símbolo de la rebeldía social? Sólo por la exclusión de este nivel de lectura. La crítica de los últimos años, entusiasmada por la actitud de Hernández de cantar opinando, ha falseado el poema, a mi juicio, de tal modo que hoy parece herejía la incuestionable verdad. Hernández, hombre de tendencia conservadora aunque reformista, no propone la modificación sustancial del mundo. Su hombre no es perfectible; siempre ha de ser igual. Pide resignación. No crea un personaje rebelde ni siquiera a la altura de sus modelos literarios románticos. El héroe no se atreve con Dios. Sólo se evidencia un afán reivindicatorio, una cierta preocupación social, un deseo de lucha por mejorar las condiciones de vida práctica. No hay intento de alterar las estructuras de la sociedad.

No es por su mensaje social por lo que vale el Martin Fierro. Vale por su visión casi inédita del mundo y de la vida, expresada de modo inigualado. El nacionalismo literario priva a Hernández de su más glorioso timbre de honor. Es decir, logra lo contrario de lo que se propone.

RUBÉN BENÍTEZ

University of California, Los Angeles. 
